\title{
Lysosomal cathepsin initiates apoptosis, which is regulated by photodamage to Bcl-2 at mitochondria in photodynamic therapy using a novel photosensitizer, ATX-s10 (Na)
}

\author{
SHUJI ICHINOSE $^{1}$, JITSUO USUDA ${ }^{1}$, TAKESHI HIRATA ${ }^{1}$, TATSUYA INOUE ${ }^{1}$, KEISHI OHTANI ${ }^{1}$, \\ SACHIO MAEHARA ${ }^{1}$, MITSUHIRO KUBOTA ${ }^{1}$, KENTAROU IMAI ${ }^{1}$, YOSHIHIKO TSUNODA ${ }^{1}$, \\ YUKARI KUROIWA ${ }^{1}$, KIMITO YAMADA ${ }^{1}$, HIDEMITSU TSUTSUI ${ }^{1}$, KINYA FURUKAWA ${ }^{2}$, \\ TETSUYA OKUNAKA ${ }^{3}$, NANCY L. OLEINICK ${ }^{4}$ and HARUBUMI KATO ${ }^{1}$ \\ ${ }^{1}$ Department of Thoracic Surgery, Tokyo Medical University, Tokyo; ${ }^{2}$ Department of Thoracic Surgery, \\ Tokyo Medical University Kasumigaura Hospital, Kasumigaura; ${ }^{3}$ Respiratory Disease Center, Sanno Hospital, \\ International University of Health and Welfare, Tokyo, Japan; ${ }^{4}$ Department of Radiation Oncology, \\ Case Western Reserve University School of Medicine, Cleveland, OH, USA
}

Received February 6, 2006; Accepted April 13, 2006

\begin{abstract}
ATX-s10 is a novel and second-generation photosensitizer for photodynamic therapy (PDT). In order to conduct clinical trials of ATX-s10-PDT and/or extend its clinical applications, it is very important to elucidate the mechanisms of the action of ATX-s10-PDT. We examined the apoptic response against ATX-s10-PDT using a Bcl-2 or Bcl-2 mutant overexpressing cells. Using fluorescent microscopy, ATX-s10 localized not only to mitochondria but also to lysosomes and possibly other intracellular organelles, but not to the plasma membrane or the nucleus. These results suggest that ATXs10-PDT can damage mitochondria and lysosomes. By Western blot analysis, ATX-s10-PDT damaged Bcl-2, which localized preferentially at mitochondrial membranes, and caused Bcl-2 to cross-link immediately after laser irradiation. However, ATX-s10-PDT was not able to rapidly induce morphologically typical apoptosis (i.e. chromatin condensation and fragmentation) as PDT using mitochondria targeted photosensitizers, such as phthalocyanine 4 (Pc 4). Pharmacological inhibitions of lysosomal cytokine protease cathepsins, such as cathepsin B and D, protected MCF-7c3 cells (human breast cancer cells expressing stably transfected procaspase-3) from apoptosis caused by ATX-s10-PDT. Overexpression of wildtype $\mathrm{Bcl}-2$ or $\mathrm{Bcl}-2 \Delta 33-54$ resulted in relative resistance of cells to ATX-s10-PDT, as assessed by the degree of morphological apoptosis or loss of clonogenicity. We conclude that lysosomal damage by ATX-s10-PDT can initiate apoptotic
\end{abstract}

Correspondence to: Dr Jitsuo Usuda, Department of Thoracic Surgery, Tokyo Medical University, 6-7-1, Nishishinjuku, Shinjuku-ku, Tokyo 160-0023, Japan

E-mail: jusuda@xc4.so-net.ne.jp

Key words: photodynamic therapy, ATX-s10(Na), Bcl-2, apoptosis, cathepsin response and this apoptotic pathway can be regulated by photodamage to $\mathrm{Bcl}-2$ via mitochondrial damage.

\section{Introduction}

Photodynamic therapy (PDT), which consists of exposing malignant lesions to a tumor-specific photosensitizer and light, is a promising modality for the treatment of a variety of solid tumors (1). Since the first modern clinical trial of PDT by Dougherty et al was reported in 1978 (2), PDT using the photosensitizer, Photofrin, has been applied to many cancer types and is approved by the US Food and Drug Administration for the treatment of advanced esophageal, early stage lung and advanced lung cancers (1). In order to enhance the efficacy of PDT and extend its clinical applications, a variety of second-generation photosensitizers are now being assessed for their efficacy in cancer therapy $(1,3)$.

We conducted a phase II clinical study to investigate the anti-tumor effects and safety of a second-generation photosensitizer, mono-L-aspartyl chlorine e6 (NPe6) in patients with centrally located early stage lung cancers (4). The study demonstrated excellent anti-tumor effects and safety, especially low skin photosensitivity. The Japanese government approved NPe6 using a diode laser for early stage lung cancer and a number of patients for indications of PDT are rapidly increasing.

It has been reported that certain photosensitizers, such as NPe6, cause an almost immediate disruption of the lysosomes after laser irradiation (5). Reiners et al reported that photodamaged lysosomes by NPe6-PDT trigger the mitochondrial apoptotic pathway by releasing proteases, cathepsin B, L and D (6), which are lysosomal cytokine proteinase and act as the main executors of caspaseindependent and/or caspase-dependent cell death (7). Gucciardi et al reported that in TNF- $\alpha$-exposed hepatocytes, caspase-8 was activated by lysosomal release of cathepsin B, which in turn mediated the release of cytochrome $\mathrm{c}$ from 
mitochondria (8). Johansson et al reported that aspartic protease, cathepsin D was a key mediator in staurosporineinduced apoptosis (9).

ATX-s10 is a second-generation photosensitizer and hydrophilic chlorine with a maximum absorption at $670 \mathrm{~nm}(10,11)$. The chemical structure of ATX-s10 is similar to that of NPe6 and they are both aspartic acid derivatives. The absorption band of ATX-s10 is at $670 \mathrm{~nm}$, which can penetrate deeper lesions than $630 \mathrm{~nm}$ wavelength required for Photofrin and $664 \mathrm{~nm}$ required for NPe6. It has been reported that PDT using ATXs10 and the diode laser had a strong anti-tumor effect and induced congestion, thrombus formation and degeneration of tumor vascular endothelial cells (10). In particular, a vascular shutdown effect plays an important role in the anti-tumor activity of ATX-s10-PDT (11). However, the precise mechanism of the anti-tumor effect of ATX-s10-PDT has not yet been elucidated.

We previously reported the construction of a series of Bcl-2 mutants and the examination of the association between their subcellular and their sensitivity to photodestruction by Pc 4PDT, which mainly damaged mitochondria and induced apoptosis $(13,14)$. We found that membrane anchorage regions were needed to form the target of Pc 4 photosensitization, and the photodamage required the region between the Bcl-2 homology 1 (BH1) and $\mathrm{BH} 2$ domains, which contains two core hydrophobic $\alpha$ helices ( $\alpha 5$ and 6) (13). Moreover, overexpression of $\mathrm{Bcl}-2$ or $\mathrm{Bcl}-2 \Delta 33-54$ resulted in relative resistance of cells to Pc 4-PDT, as assessed by morphological apoptosis or loss of clonogenicity.

In this study, in order to elucidate the molecular determinant of ATX-s10-PDT and the role of Bcl-2 in apoptotic response after lysosomal damage, we studied both transient and stable transfectants that overexpress either the wild-type Bcl-2 or a Bcl-2 mutant, and we investigated the apoptotic response via lysosomal damage and/or mitochondrial damage.

\section{Materials and methods}

Cell culture. Human breast cancer MCF-7cells transfected with human procaspase-3 cDNA (MCF-7c3 cells) were cultured in RPMI-1640 medium containing $10 \%$ fetal bovine serum (15). MCF-7c3 cells were transfected with GFP, GFPBcl-2, GFP-Bcl-2 $\Delta(33-54)$ plasmid and we isolated stable transfected cells, MCF-7c3-GFP, MCF-7c3-GFP-Bcl-2 and MCF-7c3-Bcl-2 $\Delta(33-54)$ cells using a limiting dilution method (14). These cells were cultured in RPMI-1640 medium. All cultures were maintained in a humidified atmosphere at $37^{\circ} \mathrm{C}$ with $5 \% \mathrm{CO}_{2}$.

Photosensitizers. ATX-s10Na(II) (13,17-bis 1-carboxypropionyll carba-Moylethyl-8-e thenyl-2-hydroxy-3-hydroxyimino-ethylidene-2, 7, 12, 18-tetramethyl porphyrin sodium; molecular weight: 927.79) was supplied by the Photochemical Company (Okayama, Japan). This photosensitizer has the highest absorption peak at wavelengths of $407 \mathrm{~nm}$ and a second peak at $670 \mathrm{~nm}(10,11)$. ATX-s10 was stored as powder in the dark. The ATX-s10 powder was dissolved in phosphate-buffered saline (PBS).

Laser unit. A diode laser (LD670-05; Hamamatsu Photonics K.K., Hamamatsu, Japan) emitting continuous-wave laser light at a wavelength of $670 \mathrm{~nm}$ was the light source for excitation of ATX-s10 (10,11).

Fluorescence microscopy. Fluorescence images were acquired using the handstand type fluorescence microscope (Diaphot TMD-EF2, Nikon, Tokyo) with the transfer device of a highspeed excitation light wavelength and the fluorescence imaging system by the high-speed cooling CCD camera (Panasonic Model BD 900), on the excitation Xenon light of $405 \mathrm{~nm}$, and the detection wavelength of $\geq 600 \mathrm{~nm}$ for ATXs10 $(11,14,16)$. For live cell fluorescence imaging of MCF7-c3 cells, cells were plated on 35-mm glass-bottom dishes (MatTek Corp., Ashland, MA) and incubated with $100 \mathrm{nM}$ LysoTracker Green or 100 nM MitoTracker Green (Molecular Probes, Eugene, OR) for $45 \mathrm{~min}$ at $37^{\circ} \mathrm{C}$. Images of LysoTracker Green fluorescence were collected using a 543-nm excitation light from a helium-neon (He-Ne) laser and a 560-nm long-pass filter, and images of MitoTracker Green fluorescence were collected using a 490-nm excitation light from a (He-Ne) laser and a 516-nm long-pass filter.

Clonogenic cell survival. Cells were collected from the monolayer with trypsin immediately after ATX-s10-PDT. Aliquots of the cells were seeded into $25 \mathrm{~cm}^{2}$ flasks in amounts sufficient to yield 50-150 colonies. After incubation for 10-14 days, the cells were stained with $0.1 \%$ crystal violet in $20 \%$ ethanol, and colonies containing at least 50 cells were counted (14). The plating efficiency of untreated cells was 30-40\%.

Western blot analysis. Cells were harvested by centrifugation and washed twice with ice-cold PBS. The cell pellets were incubated in a lysis buffer [50 mM Tris-HCI, pH 7.5, $120 \mathrm{mM}$ $\mathrm{NaCl}, 1 \%$ Triton $\mathrm{X}-100,0.2 \%$ sodium dodecyl sulfate (SDS), $0.5 \%$ deoxycholate, $10 \mu \mathrm{g} / \mathrm{ml}$ leupeptin, $10 \mu \mathrm{g} / \mathrm{ml}$ aprotinin, $1 \mathrm{mM}$ phenylmethylsulfonyl fluoride and $100 \mathrm{mM} \mathrm{NaF}$ ] on ice for $30 \mathrm{~min}$ and then sonicated $(13,14)$. The protein content of the whole-cell lysates was measured using the BCA protein assay reagent (Pierce, Rockford, IL). An aliquot $(20 \mu \mathrm{g})$ of the whole-cell lysate was separated by SDS-polyacrylamide gel electrophoresis (PAGE) and transferred to polyvinylidene difluoride membranes. The membranes were incubated with one of the following antibodies at appropriate concentrations for $1 \mathrm{~h}$ : Mouse monoclonal anti-Xpress (Invitrogen), mouse monoclonal anti-actin (Santa Cruz Biotechnology, Inc., Santa Cruz, CA) and hamster monoclonal anti-human Bcl-2 (Pharmingen, San Diego, CA) $(13,14)$. After rinsing with PBS containing $0.1 \%$ ( $\mathrm{vol} / \mathrm{vol}$ ) Triton $\mathrm{X}-100$, the membranes were incubated with anti-mouse or anti-hamster immunoglobulin $\mathrm{G}$ conjugated to horseradish peroxidase for $1 \mathrm{~h}$ at room temperature. The membranes were washed and developed with Western blotting-enhanced chemiluminescence detection reagents (Amersham Pharmacia Biotech, Piscataway, NJ). Independent experiments were repeated at least 3 times.

Nuclear-staining assay for apoptosis. Cells were treated with $10 \mu \mathrm{g} / \mathrm{ml} \mathrm{ATX}-\mathrm{s} 10 \mathrm{Na}$ (II) for $3 \mathrm{~h}$ and then irradiated with red light $\left(6 \mathrm{~J} / \mathrm{cm}^{2}\right)$. Six or 12 or $24 \mathrm{~h}$ after PDT, cells were collected and fixed in $1 \%$ formaldehyde. After the fixation, cells were stained with Hoechst 33342 (Molecular Probes) (14,15). At least 200 cells were counted from each sample, and the yield 
LysoTracker

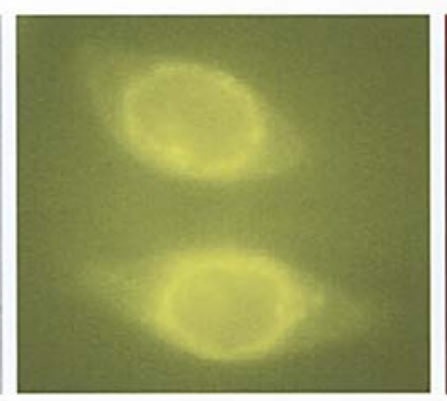

MitoTracker
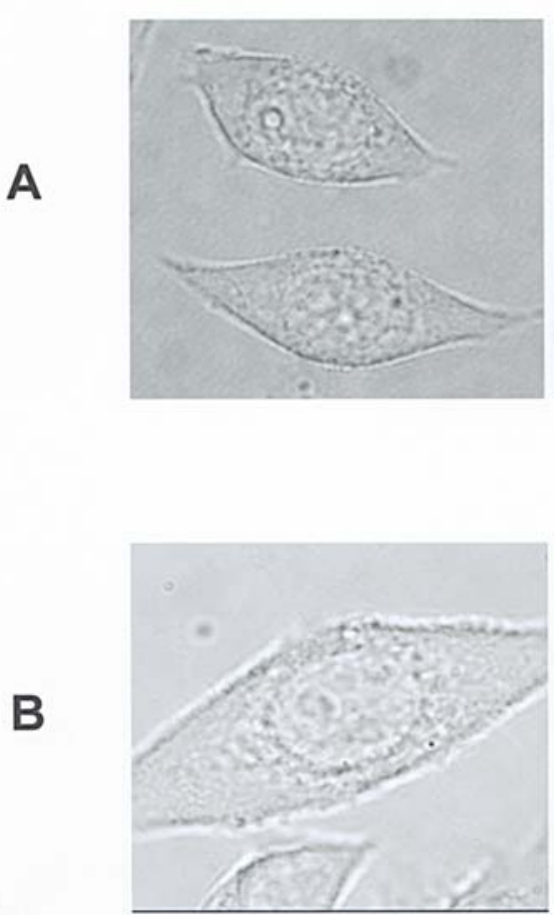

A

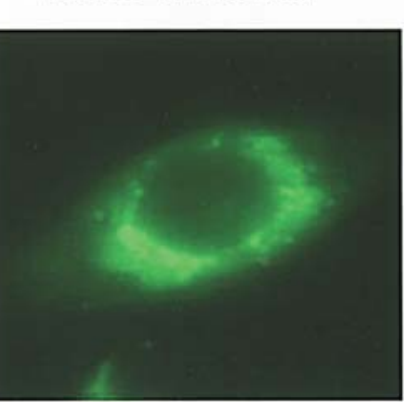

ATX-s10

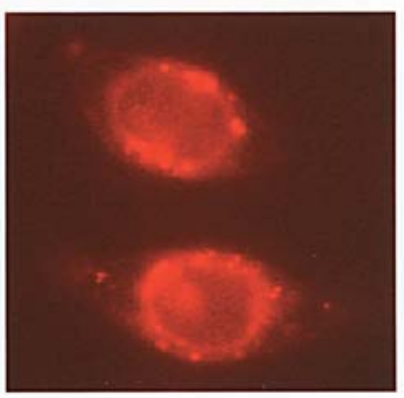

ATX-s10

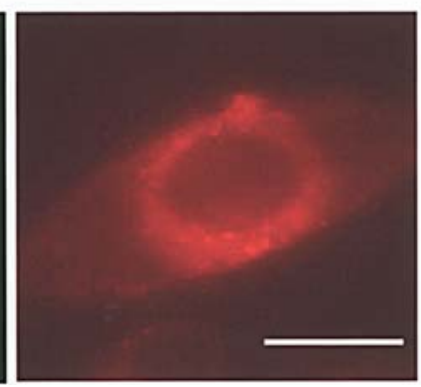

Figure 1. Localization of ATX-s10 in MCF-7c3 cells. MCF-7c3 cells were loaded with $6 \mu \mathrm{g} / \mathrm{ml}$ ATX-s10 for 3 h and $100 \mathrm{~nm}$ LysoTracker Green (A) or $100 \mathrm{~nm}$ MitoTrackerGreen (B). The images of ATX-s10 displayed a punctuate pattern, but it did not completely co-localize with LysoTracker Green (A) nor with MitoTracker Green (B). Scale bar, $5 \mu \mathrm{m}$.

of apoptotic cells was expressed as a percentage of the total population. Independent experiments were repeated at least 3 times.

Apoptotic response after treatment of cathepsin inhibitor. The influence of apoptosis on ATX-s10-PDT after each cathepsin B or D inhibitor addition was observed. Cells were

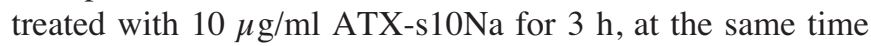
were added by each cathepsin B inhibitor CA-074Me (Peptides International, Osaka, Japan) at final concentrations of $100 \mu \mathrm{M}, \mathrm{zFA}-\mathrm{fmk}$ (Enzyme Systems Product) at $200 \mu \mathrm{M}$, or cathepsin D inhibitor Pepstatin A (Signa Chemicals, St. Louis, MO) at $100 \mu \mathrm{M}$, and then irradiated with red light $\left(6 \mathrm{~J} / \mathrm{cm}^{2}\right)(17,18)$. Twenty four hours after PDT, cells were collected and fixed in $1 \%$ formaldehyde. After the fixation, cells were stained with Hoechst 33342 (Molecular Probes). At least 200 cells were counted from each sample using fluorescent microscopy, and the yield of apoptotic cells was expressed as a percentage of the total population. Independent experiments were repeated at least 3 times.

\section{Results}

ATX-s10 localizes to mitochondria and other intracellular organelles of $\mathrm{MCF}-7 \mathrm{c} 3$ cells. In cancer cells, PDT causes oxidative damage in target molecules that reside within a few $\mathrm{nm}$ of the sites of photoactivation of the photosensitizer $(13,17)$. In order to elucidate the mechanism of the action of PDT, it has been reported that the localization of the photosensitizer is important (17). The chemical structure of a novel and second-generation photosensitizer, ATX-s10, is similar to that of NPe6 which preferentially localizes to lysosome. Therefore, we first investigated the localization of ATX-s10 in MCF-7c3 cells using fluorescence microscopy (Fig. 1A). In order to assess whether ATX-s10 binds to the lysosome, MCF7c3 cells were co-loaded with LysoTracker Green, a lysosomespecific dye (Fig. 1A). The images of ATX-s10 displayed a punctate pattern, but ATX-s10 fluorescence only partially co-localized with LysoTracker Green fluorescence. Fig. 1B shows MCF-7c3 cells co-loaded with MitoTracker Green, a mitochondrion-specific dye. ATX-s10 fluorescence only partially co-localized with MitoTracker Green fluorescence (Fig. 1B). These results indicate that in MCF-7c3 cells ATXs10 localizes not only to mitochondria but also to lysosomes, the endoplasmic reticulum (ER), Golgi complexes and possibly other intracellular organelles, but not to the plasma membrane or the nucleus, as previously reported $(10,11$, $18,19)$. These results suggest that ATX-s10-PDT has effects on lysosomes and mitochondria.

ATX-s10-PDT using diode laser damages the anti-apoptotic protein $\mathrm{Bcl}-2$. We used pcDNA4/HisMax plasmid, which encodes the Xpress ${ }^{\mathrm{TM}}$ epitope at the $\mathrm{N}$-terminal region of the multiple cloning sites and we transiently transfected pcDNA4/ HisMax-full-length human Bcl-2 (239 amino acids) into MCF$7 \mathrm{c} 3$ cells, as previously reported $(13,14)$. Twenty-four hours after transfection, we performed PDT using a diode laser with the dose killing $92 \pm 8 \%$ of the $\mathrm{MCF}-7 \mathrm{c} 3$ cells, as determined by clonogenic assay. The extent of photodamage was assessed by Western blot analysis (Fig. 2). The overexpressed wild-type Bcl-2 was immediately photodamaged by ATXs10-PDT and formed high molecular weight cross-linked 


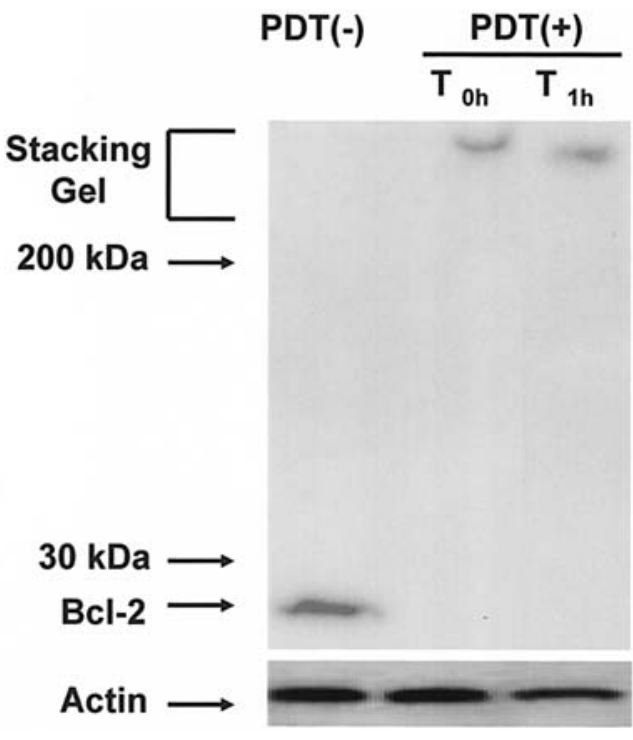

Figure 2. Photodamage to Bcl-2 in MCF-7c3 cells by ATX-s10-PDT. MCF$7 \mathrm{c} 3$ cells were transiently transfected with the pcDNA/HisMax expression vector containing wild-type Bcl-2. Twenty hours after transfection, the cells were treated with ATX-s10 $(6 \mu \mathrm{g} / \mathrm{ml})$ for $3 \mathrm{~h}$ and then photoirradiated with laser $\left(670 \mathrm{~nm}, 6 \mathrm{~J} / \mathrm{cm}^{2}\right)$, producing $92 \pm 3 \%$ killing of MCF-7c3 cells. Immediately or $1 \mathrm{~h}$ after PDT, cells were collected, washed and lysed. The protein content of the whole cell lysates was measured using the BCA protein assay reagent. An aliquot $(20 \mu \mathrm{g} / \mathrm{ml})$ of the whole cell lysate was separated by SDS-PAGE. The level of Bcl-2 was examined by Western blot analysis using a mouse monoclonal anti-Xpress tag antibody before PDT, immediately after PDT $\left(\mathrm{T}_{0 \mathrm{~h}}\right)$, and $1 \mathrm{~h}\left(\mathrm{~T}_{1 \mathrm{~h}}\right)$ after ATX-s10-PDT. The dose of PDT (the control) received ATX-s10 but was not irradiated.

protein complexes as we have previously reported using Pc4-PDT $(13,14)$. These results indicate that ATX-s10-PDT damages Bcl-2 in the same way as Pc 4-PDT, which can damage mitochondria but not lysosomes, and our data suggest that the mechanism of action of ATX-s10-PDT may be different from that of NPe6-PDT, which damages lysosomes (5,17-19).

Bcl-2-overexpressing cells were resistant to loss of clonogenicity. We previously isolated and characterized clones of MCF-7c3 cells stably overexpressing high levels of GFPBcl-2 and GFP-Bcl-2 ( $133-54)$ (14). MCF-7c3-GFP-Bcl-2 cells had on the order of 50x the levels of Bcl-2 of the parental MCF-7c3 cells. We evaluated the sensitivity of MCF-7c3-GFP cells to ATX-s10-PDT by clonogenic assay. The survival curves (Fig. 3) indicate that MCF-7c3 cells overexpressing GFP-Bcl-2 or GFP-Bcl-2 $(\Delta 33-54)$ were considerably more resistant to the lethal effects of ATX-s10PDT than were parental MCF-7c3 cells. At the 10\% survival level, the presence of $\mathrm{Bcl}-2$ provided a dose-modifying factor of $\sim 1.2$. These results suggest that $\mathrm{Bcl}-2$ exerts a marked regulatory effect on the cell survival of ATX-s10-PDT.

ATX-s10-PDT did not rapidly induce typical apoptosis in $M C F-7 c 3$ cells. In order to examine whether the stable expression of Bcl-2 and/or Bcl-2 mutant protein, Bcl-2 $\Delta 33$ 54, can protect against apoptosis induced by ATX-s10-PDT, we estimated apoptosis by monitoring nuclear morphology after staining with Hoechst 33342 (Table I). When we tried to damage Bcl-2 in MCF-7c3 cells under conditions of an $\mathrm{LD}_{90}$
Table I. Protection by Bcl-2 mutants against ATX-s10-PDTinduced apoptosis.

\begin{tabular}{lcccc}
\hline Cells & Control & $6 \mathrm{~h}$ & $12 \mathrm{~h}$ & $24 \mathrm{~h}$ \\
\hline MCF-7c3 & $1.7 \pm 0.5$ & $5.6 \pm 2.4$ & $18.3 \pm 2.4$ & $88.3 \pm 5.2$ \\
GFP-Bcl-2 & $1.7 \pm 0.7$ & $4.5 \pm 3.7$ & $14.2 \pm 3.3$ & ${ }^{\mathrm{a}} 17.8 \pm 3.1$ \\
GFP-Bcl-2 & $0.8 \pm 0.8$ & $3.6 \pm 3.1$ & $13.3 \pm 3.1$ & ${ }^{\mathrm{a}} 17.2 \pm 10$ \\
$\Delta 33-54$ & & & & \\
GFP-Bcl-2 & $1.4 \pm 1.5$ & $4.8 \pm 0.8$ & $16.5 \pm 6.6$ & $78.3 \pm 9.5$ \\
$\Delta 210-239$ & & & & \\
\hline
\end{tabular}

Cells were treated with $6 \mathrm{pg} / \mathrm{ml} \mathrm{ATX-s10} \mathrm{for} 3 \mathrm{~h}$ and then irradiated with diode laser $\left(6 \mathrm{~J} / \mathrm{cm}^{2}\right)$. The dose of PDT used in experiments $\left(6 \mu \mathrm{g} / \mathrm{ml} \mathrm{ATX}-\mathrm{s} 10+6 \mathrm{~J} / \mathrm{cm}^{2}\right.$ laser irradiation) was demonstrated to produce $92 \pm 3 \%$ killing of MCF-7c3 cells, as determined by clonogenic assay (Fig. 3). Six, 12, $24 \mathrm{~h}$ after PDT, cells were collected and fixed. After fixation, cells were stained with Hoechst 33342. At least 200 cells were counted from each sample, and yield of apoptotic cells was expressed the percentage of the total population. Independent experiments were repeated at least 3 times. ${ }^{\text {a Significantly }}$ different from MCF-7c3 cells $24 \mathrm{~h}$ after PDT $(\mathrm{p}<0.05)$.

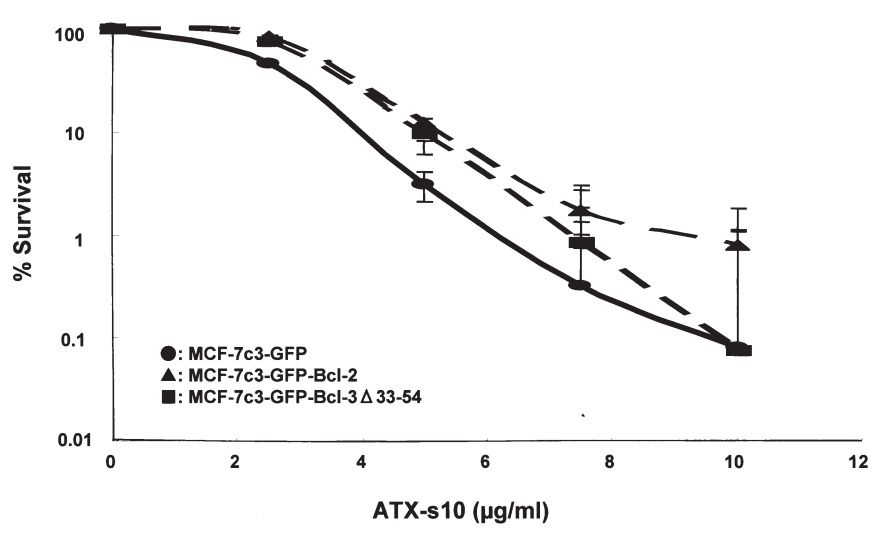

Figure 3. Loss of clonogenicity of MCF-7c3 cells as a result of ATX-s10PDT. Exponentially growing cultures of each cell line were treated with 2.5 , $5,7.5$ and $10 \mu \mathrm{g} / \mathrm{ml}$ ATX-s 10 for $3 \mathrm{~h}$, and then irradiated with $6 \mathrm{~J} / \mathrm{cm}^{2}$, 670-nm laser light. Immediately after PDT, cells were trypsinized, collected, diluted and plated. Data for PDT-treated cells were normalized to plating efficiency of untreated cells of the same cell line. Each datum is the mean \pm standard deviation for results from three independent experiments. MCF-7c3 cells (solid dots), MCF-7c3-Bcl-2 cells (solid triangles) and MCF-7c3-Bcl2 $\Delta 33-54$ cells (solid squares).

PDT dose, typical apoptosis was $<30 \%$ after $6 \mathrm{~h}$. We previously reported that Pc 4-PDT damaged mitochondria and lead to rapid release of cytochrome $\mathrm{c}$ and rapidly induced typical apoptosis. Five hours after Pc 4-PDT, almost 30\% of MCF$7 \mathrm{c} 3$ cells were in apoptosis in the condition of $\mathrm{LD}_{90}$ doses. However, in MCF-7c3-GFP cells, 5-8\% and 90\% of cells were in apoptosis within 6 and $24 \mathrm{~h}$ respectively and ATXs10-PDT took longer time to induce morphologically typical apoptosis compared with Pc 4-PDT (Fig. 4). These results suggest that the apoptotic pathway caused by ATX-s10 may 
Before PDT

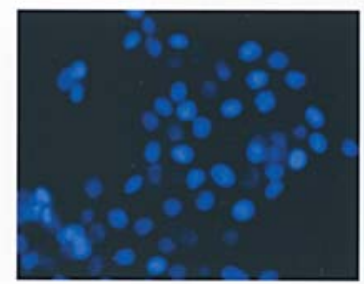

Apoptosis (\%) $\quad 1.7 \pm 0.5$
$6 \mathrm{~h}$

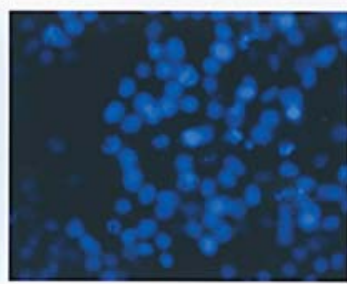

$5.6 \pm 2.4$
$12 \mathrm{~h}$

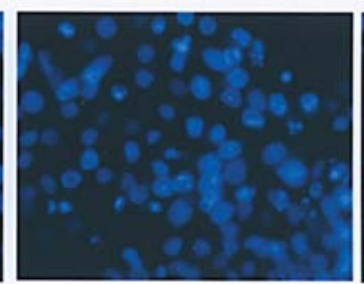

$18.3 \pm 2.4$
$24 \mathrm{~h}$

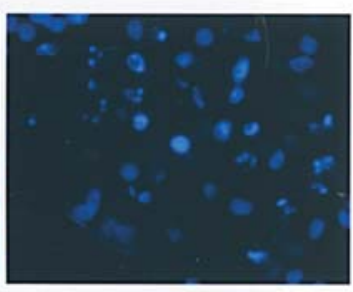

$88.3 \pm 5.2$

Figure 4. ATX-s10-PDT induced morphologically typical apoptosis. MCF-7c3 cells were treated with $6 \mu \mathrm{g} / \mathrm{ml}$ ATX-s 10 for $3 \mathrm{~h}$ and then photoirradiated with red laser $\left(670 \mathrm{~nm}, 6 \mathrm{~J} / \mathrm{cm}^{2}\right)$, producing $99 \%$ killing of MCF-7c3 cells, as determined by clonogenic assay. Six, 12 , or $24 \mathrm{~h}$ after PDT, cells were collected and fixed. After fixation, cells were stained with Hoechst 33342. At least 200 cells were counted from each sample. The yield of apoptotic cells was expressed as a percentage of the total population.

$(-)$

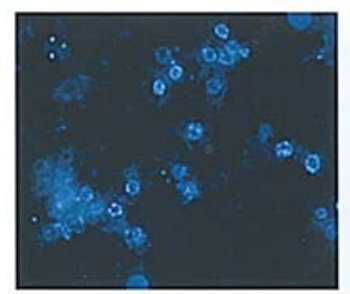

$88.2 \pm 10.5$
CA-074Me

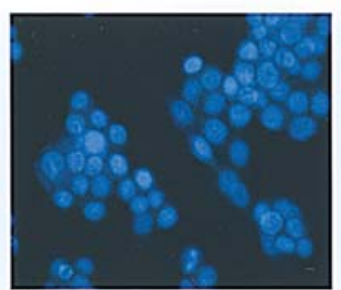

$2.9 \pm 1.5$
zFA-fmk

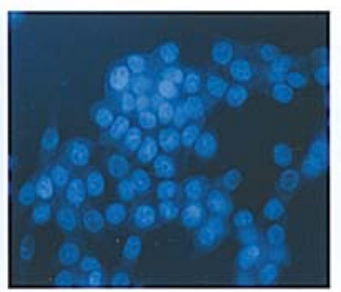

$2.4 \pm 1.7$
Pepstatin A

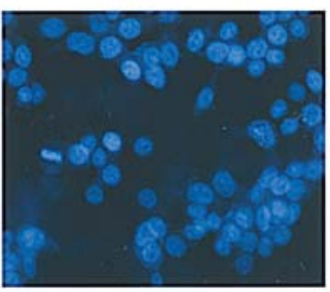

$3.6 \pm 2.5$

B

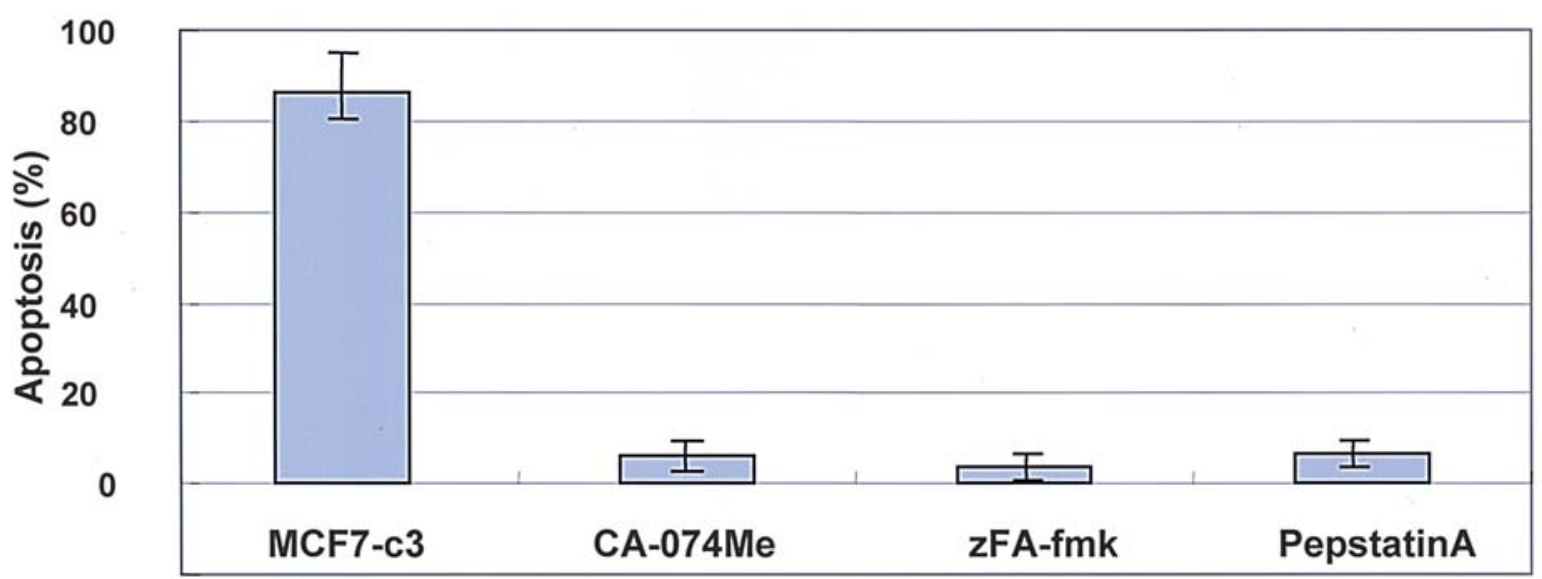

Figure 5. Inhibition of cathepsin can protect against ATX-s10-induced apoptosis. (A) MCF-7c3 cells were treated with $6 \mu \mathrm{g} / \mathrm{ml}$ ATX-s10 and $100 \mu \mathrm{M}$ CA074Me or $200 \mu \mathrm{MzFA}-\mathrm{fmk}$ or $100 \mu \mathrm{M}$ Pepstatin A for $3 \mathrm{~h}$, and then were photoirradiated with a diode laser $\left(670 \mathrm{~nm}, 6 \mathrm{~J} / \mathrm{cm}^{2}\right)$. After PDT, cells were washed and then treated with CA-074Me or MzFA-fmk or Pepstatin A. Twenty-four hours after PDT, cells were washed, collected and fixed, then stained with Hoechst 33342. At least 200 cells were counted from each sample, the yield of apoptotic cells was expressed as a percentage of the total population. (B) The morphologically typical apoptosis. The results represent the mean and SD of at least three independent experiments.

be different from that of Pc 4-PDT. We hypothesized that lysosomal damage may trigger the apoptotic signal after ATX-s10-PDT.

In MCF-7c3-GFP-Bcl-2 cells, MCF-7c3-GFP-Bcl-2 $133-54$ cells, apoptotic rates were $<20 \% 24 \mathrm{~h}$ after ATX-s10-PDT. These data suggest that overexpression of Bcl-2 and Bcl2 $\Delta 33-54$ protect against apoptosis induced by ATX-s10PDT. It has been reported that in the process of apoptosis, Bcl-2 protein can be cleaved at Asp34 by caspase- 3 and the cleaved Bcl-2 is converted to a Bax-like proapoptotic effector $(20,21)$. Our data suggest that such a cleavage does not appear to be important for ATX-s10-PDT-induced cell death.

Inhibition of cathepsin B and D potently protects against ATXs10-PDT-induced apoptosis. We have reported that $17-20 \%$ of MCF-7c3-GFP cells were in apoptosis $5 \mathrm{~h}$ after Pc 4-PDT at $\mathrm{LD}_{90}$ dose (14). Fig. 3 shows a few typical apoptosis (5-8\%) in MCF-7c3-GFP cells $6 \mathrm{~h}$ after ATX-s10-PDT at $\mathrm{LD}_{90}$ dose. 
Twelve hours after PDT, 17-20\% of MCF-7c3 cells were in apoptosis. These results indicate that ATX-s10-PDT induced apoptosis slowly and that the mechanism of the action of ATX-s10-PDT may be different from that of Pc 4-PDT. We hypothesized that ATX-s10-PDT may damage lysosomes first, then trigger the mitochondrial apoptotic pathway by releasing proteases from lysosome.

In order to investigate lysosomal protease-dependent pathways of apoptosis caused by ATX-s10-PDT, we screened several protease inhibitors for their ability to interfere with PDT-induced apoptosis in MCF-7c3 cells. Fig. 5A and B showed that inhibition of cathepsin $\mathrm{B}$ by the selective chemical inhibitors CA-074 Me and zFA-fmk, and cathepsin D inhibitors, Pepstatin A, strongly protected MCF-7c3-GFP cells from induction of apoptosis by ATX-s10-PDT (7-9). These results suggest that lysosomal protease cathepsin B and D play key roles in apoptotic pathways after ATX-s10-PDT.

\section{Discussion}

It was reported that PDT using certain photosensitizers induced apoptosis and/or necrosis $(1,17)$. Many investigators have reported that the two types of cell death depend on the nature of the photosensitizers, the subcellular localizations of the photosensitizers, cell types, treatment conditions (17,22-24). Nagata et al reported that PDT with higher doses of laser irradiation and ATX-s10 can preferentially induce necrosis and lower doses can induce apoptosis (18). It was difficult to quantify the exact ratio of apoptosis in our data after ATXs10-PDT. In MCF-7c3-GFP-Bcl-2 cells and MCF-7c3-GFPBcl-2 $\triangle 33-54$ cells, ATX-s10-PDT did not largely induce apoptosis (17.8\%) compared to MCF-7c3-GFP cells (88.3\%). However, in the clonogenic assay, MCF-7c3-GFP-Bcl-2 cells and MCF-7c3-GFP-Bcl-2 $\Delta 33-54$ cells were not very resistant to parental MCF-7c3-GFP cells (Fig. 3), as previously reported using Pc 4 (14). From these data, we speculated that in Bcl-2 overexpressing cells, the rates of apoptosis might be low and ATX-s10-PDT might largely induce necrosis. Bcl-2 may regulate the ratio of apoptosis after ATX-s10-PDT. Further investigations of the mechanism of apoptosis following ATX-s10-PDT are needed.

Photofrin and Pc 4 preferentially accumulate in mitochondria and induce apoptosis via the release of apoptotic inducing factors (AIF) such as cytochrome c. The induced apoptosis was observed rapidly after PDT (13-15). NPe6 preferentially accumulate to lysosomes and NPe6-PDT does not damage mitochondria $(5,6)$. Kessel et al reported that photosensitizers such as NPe6 that localized in lysosomes did not cause photodamage to the anti-apoptotic protein Bcl-2, but induced apoptosis through the release of lysosomal cathepsins $(5,6,25)$. In our data, ATX-s10 localized to mitochondria and lysosomes, and ATX-s10-PDT can damage Bcl-2 but did not rapidly induce typical apoptosis (Fig. 4). ATX-s10-PDT took considerable time to cause morphologically typical apoptosis as previously reported (18). The features of this novel photosensitizer, ATX-s10, is different from those of Photofrin and NPe6.

Nagata et al and Mori et al also reported that AXT-s10 localizes in mitochondria and lysosomes, and ATX-s10-PDT can induce necrosis and apoptosis in tumors $(10,18)$. However, it is unclear whether ATX-s10-PDT preferentially damages mitochondria or lysosomes, and whether ATX-s10-PDT can preferentially cause necrosis or apoptosis. ATX-s10-PDT damaged Bcl-2 at mitochondria immediately after laser irradiation (Fig. 2) and overexpressions of Bcl-2 cells were resistant to the susceptibility of the anti-tumor effect of ATXs10-PDT (Fig. 3). These results suggest that Bcl-2 regulate the anti-tumor effect of ATX-s10-PDT. Figs. 4 and 5 show that ATX-s10-PDT did not rapidly induce apoptosis in cancer cells as Nagata et al previously reported (18), and cathepsin inhibitors protected against ATX-s10-induced apoptosis. These results suggest that apoptosis induced by ATX-s10-PDT may depend upon the damage of lysosomes. Stoka et al reported that lysosomal damage may inactivate lysosomal protease or leaked lysosomal protease may decrease mitochondrial transmembrane potential (25). We hypothesized that ATX-s10PDT may initiate the apoptotic response through direct damage of lysosomes, and can regulate cell death through the photodamage of Bcl-2 by direct and indirect damage of mitochondria.

We have shown that cells overexpressing Bcl-2 or Bcl$2 \Delta 33-54$ are resistant to the induction of apoptosis and to the overall lethal effects of ATX-s10-PDT. These data are similar to our previous observations that overexpressing Bcl-2 made MCF-7c3-GFP-Bcl-2 cells more resistant to apoptosis and the loss of clonogenicity on exposure to Pc 4-PDT. (14) An important question is why cells overexpressing $\mathrm{Bcl}-2$ are resistant to the induction of PDT-induced apoptosis. Bcl-2 may act in an antioxidant pathway or may block the release of cytochrome c to interfere with apoptosis caused by ATXs10-PDT $(14,26,27)$. It is still unclear whether photodamaged $\mathrm{Bcl}-2$ retains its anti-apoptotic functions. We previously reported that MCF-7c3-GFP-Bcl-2 cells expressed high levels of Bcl-2 protein (14), and abnormally high doses of ATX-s10 or laser irradiation were required to reduce Bcl-2 level and elevated the Bax-Bcl-2 ratio. Therefore, we suggest that a standard PDT dose may be sufficient to damage all Bcl-2 in tumors and ATX-s10-PDT can overcome the resistance against anti-cancer therapies.

We conclude that ATX-s10-PDT can damage mitochondria and lysosomes, and the damage of lysosomes can initiate the apoptotic pathway, which can be regulated by the photodamage of Bcl-2 in mitochondria.

\section{Acknowledgements}

This work was supported in part by Grant-in-Aid for Young Scientist (B) from the Ministry of Education, Culture, Sports, Science and Technology (MEXT) KAKENHI 16790802 (J.U.).

\section{References}

1. Dougherty TJ, Gomer CJ, Barbara WH, et al: Photodynamic therapy. J Natl Cancer Inst 90: 889-905, 1998.

2. Dougherty TJ, Lawrence G, Kaufman JH, et al: Photoradiation in the treatment of recurrent breast carcinoma. J Natl Cancer Inst 62: 231-237, 1979.

3. Dougherty TJ: An update on photodynamic therapy applications. J Clin Laser Med Surg 20: 3-7, 2002.

4. Kato H, Furukawa K, Sato M, et al: Phase II clinical study of photodynamic therapy using mono-L-aspartyl chlorine e6 and diode laser for early superficial squamous cell carcinoma of the lung. Lung Cancer 42: 103-111, 2003. 
5. Kessel D, Luo Y, Mathieu P, et al: Determinants of apoptosis response to lysosomal photodamage. Photochem Photobiol 71: 196-200, 2000.

6. Reiners JJ, Caruso JA, Mathieu P, et al: Release of cytochrome c and activation of procaspase-9 following lysosomal photodamage involves Bid cleavage. Cell Death Differ 9: 934-944, 2002.

7. Broker LE, Huisman C, Span SW, et al: Cathepsin B mediates caspase-independent cell death induced by microtubule stabilizing agents in non-small cell lung cancer cells. Cancer Res 64: 27-30, 2004

8. Guicciardi ME, Deussing J, Miyoshi H, et al: Cathepsin B contributes to TNF-alpha-mediated hepatocyte apoptosis by promoting mitochondrial release of cytochrome c. J Clin Invest 106: 1127-1137, 2000.

9. Johansson AC, Steen H, Ollinger K, et al: Cathepsin D mediates cytochrome $\mathrm{c}$ release and caspase activation in human fibroblast apoptosis induced by staurosporine. Cell Death Differ 10: 1253-1259, 2003.

10. Mori M, Sakata I, Hirano T, et al: Photodynamic therapy for experimental tumors using ATX-s10 (Na), a hydrophilic chlorine for photosensitizer, and diode laser. Jpn J Cancer Res 91: 753-759, 2000.

11. Masumoto K, Yamada I, Tanaka H, et al: Tissue distribution of a new photosensitizer ATX-s10Na (II) and effect of a diode laser $(670 \mathrm{~nm})$ in photodynamic therapy. Lasers Med Sci 18 : $134-138,2003$.

12. Huang Y, Obana A, Gohto Y, et al: Comparative study of the phototoxicity of two chrolin type photosensitizers, ATX-s10 (Na) and Verteporfin, on vascular endothelial and retinal pigment epithelial cells. Lasers Surg Med 34: 2116-2226, 2004.

13. Usuda J, Chiu SM, Murphy ES, et al: Domain-depend photodamage to Bcl-2: A membrane anchorage region is needed to form the target of phthalocyanine. J Biol Chem 278: 2021-2029, 2003.

14. Usuda J, Azizuddin K, Chiu SM, et al: Association between the photodynamic loss of $\mathrm{Bcl}-2$ and the sensitivity to apoptosis caused by phthalocyanine photodynamic therapy. Photochem Photobiol 78: 1-8, 2003.

15. Usuda J, Chiu SM, Azizuddin K, et al: Promotion of photodynamic therapy-induced apoptosis by the mitochondrial protein Smac/DIABLO: dependence on Bax. Photochem Photobiol 76: 217-223, 2002.
16. Usuda J, Okunaka T, Furukawa K, et al: Increased cytotoxic effects of photodynamic therapy in IL-6 gene transfected cells via enhanced apoptosis. Int J Cancer 93: 475-480, 2001.

17. Oleinick NL, Morris RL and Belichenko I: The role of apoptosis in response to photodynamic therapy: what, where, why, and how. Photochem Photobiol Sci 1: 1-21, 2001.

18. Nagata S, Obana A, Gohto Y, et al: Necrotic and apoptotic cell death of human malignant melanoma cells following photodynamic therapy using an amphiphilic photosensitize, ATX-s10 (Na). Lasers Surg Med 33: 64-70, 2003.

19. Yamamoto J, Hirano T, Li S, et al: Selective accumulation and strong photodynamic effects of a new photosensitize, ATX-s10 $\mathrm{Na}$ (II), in experimental malignant glioma. Int J Oncol 27: 1207-1213, 2005.

20. Cheng EH-Y, Kirsch DG, Chen RJ, et al: Conversion of Bcl-2 to a Bax-like death effector by caspase. Science 278: 1966-1968, 1997.

21. Kirsch DG, Kastan MB, Lazebnik Y, et al: Caspase-3-dependent cleavage of Bcl-2 promotes release of cytochrome c. J Biol Chem 274: 21155-21161, 1999.

22. Luo Y, Chang CK and Kessel D: Rapid initiation of apoptosis by photodynamic therapy. Photochem Photobiol 63: 528-534, 1996.

23. Berg K and Moan J: Lysosomes and microtubles as targets for photochemotherapy of cancer. Photochem Photobiol 65: 403-409, 1997.

24. Fabris C, Valduga G, Miotto G, et al: Photosensitization with zinc (II) phthalocyanine as a switch in the decision between apoptosis and necrosis. Cancer Res 61: 7495-7500, 2001.

25. Stoka V, Turk B, Schendel SL, et al: Lysosomal protease pathways to apoptosis. J Biol Chem 276: 3149-3157, 2001.

26. Hockenbery DM, Oltvai ZN, Yin XM, et al: Bcl-2 functions in an antioxidant pathway to prevent apoptosis. Cell 75: 241-251, 1993.

27. Burkit MJ and Wardman P: Cytochrome $\mathrm{c}$ is a potent catalyst of dichlorofluorescin oxidation: implications for the role of reactive oxygen species in apoptosis. Biochem Biophy Res Commun 282: 329-333, 2001 